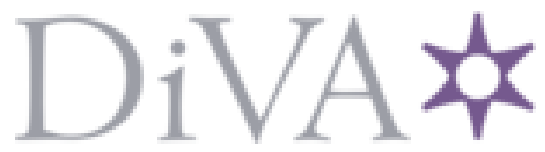

http://www.diva-portal.org

This is the published version of a paper presented at SPE International Conference and Exhibition on Health, Safety, Environment, and Sustainability, July 27-30, 2020, Virtual.

Citation for the original published paper:

Franca, J., Zerfass, H., Silveira, M. (2020)

Bringing Safety to the Field: Safety Engineers and Geologists Working Together in Outcrops

In: Society of Petroleum Engineers (ed.), SPE International Conference and Exhibition on Health, Safety, Environment, and Sustainability, July 2020, Virtual, SPE-199385MS Society of Petroleum Engineers https://doi.org/10.2118/199385-MS

N.B. When citing this work, cite the original published paper.

Permanent link to this version:

http://urn.kb.se/resolve?urn=urn:nbn:se:Inu:diva-100413 


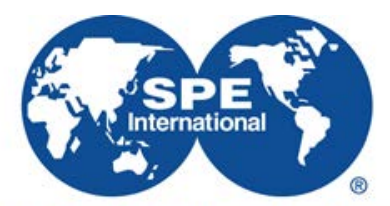

Society of Petroleum Engineers

\title{
SPE-199385-MS
}

\section{Bringing Safety to the Field: Safety Engineers and Geologists Working Together in Outcrops}

\author{
Josue Franca, Henrique Zerfass, and Miguel Silveira, Petrobras - Petroleo Brasileiro SA \\ Copyright 2020, Society of Petroleum Engineers
}

This paper was prepared for presentation at the SPE International Conference and Exhibition on Health, Safety, Environment, and Sustainability originally scheduled to be held in Bogota, Colombia, 17 - 19 March 2020. Due to COVID-19 the physical event was postponed until $27-31$ July 2020 and was changed to a virtual event. The official proceedings were published online on 20 July 2020.

This paper was selected for presentation by an SPE program committee following review of information contained in an abstract submitted by the author(s). Contents of the paper have not been reviewed by the Society of Petroleum Engineers and are subject to correction by the author(s). The material does not necessarily reflect any position of the Society of Petroleum Engineers, its officers, or members. Electronic reproduction, distribution, or storage of any part of this paper without the written consent of the Society of Petroleum Engineers is prohibited. Permission to reproduce in print is restricted to an abstract of not more than 300 words; illustrations may not be copied. The abstract must contain conspicuous acknowledgment of SPE copyright.

\section{Abstract}

Exploration, drilling and production are the main activities of upstream segment and defines strategy, guidelines and budgets of many O\&G companies. However, none of these can happens without an important first step, where there is a huge work from geocientists: the field geological studies, where for years geologists, geophysicists and petroleum engineers have studied surface outcrops together to determine subsurface geological models for oil reservoirs. Although this work on outcrops is also part of the O\&G segment, and has also been developed for years and years, the safety culture of these sites is not the same as on oil rigs, offshore platforms and onshore oil fields.

In this sense, and seeking to add value for people and build a new safety culture, the present study puts in place a new element to this equation, having safety engineers and geoscientists - mainly geologists and geophysicists - developing together all the activities of geology field studies, promoting a new safer way to carry out an important and necessary study for the entire upstream chain. Thus, the aim of this study is to present the results that emerged from the teamwork between safety engineers and geologists, in the geoscience training activities of field courses in several outcrops in Brazil, South Africa and Argentina. These field courses are part of a main training program for geologists, geophysicists, petroleum engineers and other related professionals, coordinated by a corporate university of an integrated petroleum company, with national and international operation.

\section{Introduction}

Observation and interpretation of geological objects have been the core of geoscientists work methodology since the early days of geosciences development. This observation is not a simple contemplation, but a detailed analysis oriented by theories using mental models and conceptual tools, in order to understand phenomena and mechanisms in the surface interpretations, of what is, or happens, in the subsurface of the Earth. In a similar approach of observation and comprehension, safety engineers have developed several risk assessments, where they identify hazards and develop protective and mitigating measures for the consecutive risks, always focused on protecting people and environment. According to Forrester et al (2018) recreational climbing occurs along a spectrum, from relatively low-risk indoor rock climbing to inherently 
higher risk activities such as technical mountaineering. Comparing these activities with the geology field activities, depending on the outcrop, also involve low-risk and hi-risks situations.

When safety engineers and geologists work together, in outcrops, the activity is observed from a wider perspective, having safety arising as the element of connection and interaction in the field. Therefore, hazardous elements that could not recognized individually, for example power lines over the trees and poisonous foliage, are recognized together. For safety engineers, the interaction between geoscientists and outcrops is rather complex, giving rise to a deep and scientific understanding of Earth. On the other hand, in working in the field with safety engineers, geoscientists increase their perception of risk, and hazardous elements, out of context or seemingly latent risks, become evident and are properly evaluated.

The interaction between these professionals creates a safer and more complete field-training environment, in the sense that not only the scientific geological knowledge is developed, but also safety knowledge, creating a unique learning context. In this way, the same safety commitment that is present in the upstream and downstream activities of the O\&G industry emerges as a value in the field training activities in geosciences. Moreover, this interaction and exchange of expertise, having safety in mind, builds a unique and integrated safety culture that reverberates from field training to operating activities.

\section{The Evolution of Field Geology}

The geology field activities are as old as humanity's demand for mineral resources. In ancient Egypt, rocks for the construction of large temples and monuments were pragmatically prearranged near the site, but if raw materials were not available nearby, architects would not hesitate to request materials from remote areas (Klemm \& Klemm, 2001). This shows that fieldwork for mineral prospecting in the kingdom's territory was necessary and systematic. In modern times, the great discoveries of geology are directly related to fieldwork. Considered the father of geology, James Hutton (1726-1797) was a farmer in Scotland and, on many walks around his estate, observed and interpreted the rocks, soils and geological processes that shape the surface. In addition, he undertook geological expeditions to make observations that constituted material for his Theory of the Earth. The first geological map of the world, encompassing England, Wales and part of Scotland, was published in 1815 by self-taught topographer and geologist William Smith; Data for mapmaking was collected in many years of fieldwork when Smith devoted himself to building canals (Winchester, 2004).

The foundations for modern stratigraphy were laid in the fieldwork of two nineteenth-century geologists. Amanz Gressly undertook two years of fieldwork in the Jura region of Switzerland when he observed that sedimentary rock layers have lateral facies variations and for the first time pointed to the distinction between lithologies and timelines (Cross, 1997). Johannes Walther traveled to regions such as the Mediterranean and the Middle East to observe current sedimentation environments, which provided input for his conceptualization of facies treatment (Schwab, Hauschke, \& Hellmund, 2012). The geology in the Americas has also come to be known through fieldwork, such as the expeditions of naturalists Alexander Von Humboldt and Charles Darwin to the Andes. Grove Karl Gilbert's expeditions to western North America in the second half of the nineteenth century greatly contributed not only to the knowledge of that region, but also to geomorphology in general. Also, Alexander Du Toit's field trip in the 1920s to Brazil, Uruguay and Argentina, made a great contribution to the foundations of modern geology. A fine connoisseur of South African geology, he made a comparison with South American geology, corroborating Wegener's theory of continental drift, anticipating plate tectonics by more than three decades (Du Toit, 1952).

\section{Understanding the Risks of Geology Field Activities}

The geology field studies are a differentiated activity, and it cannot be confused with a common activity of a common industry or factory routine or work environment. This activity, in terms of safety, cannot be summarized by steeltoe boot, hardhats and operating procedures; It is much more than that. In fact, the geology field studies are a mixture of explorer, scientist and naturalist, as they interact with nature in a 
different way, gathering information, generating models, validating theories. Although O\&G geoscientists work directly with engineers, technicians and other professionals who assist in the process of oil exploration and production, in places such as platforms, research centers and laboratories, their work has a different interaction with rocks than other workers. It is necessary to touch and interact with the rock, gravel and samples, which makes the conventional protection barriers present in regular process industries not enough for geoscientists.

Thus, the effective prevention of those risks in the outcrops depends on thorough understanding and observation of the risks in the field, amalgamating the expertise of geologists and safety engineers. For Vanpoulle, Vignac, \& Soulé (2017), in the outdoor activities, accidents usually proceed from the interaction of various, sometimes scattered causes or factors, rooted in different time scales. For example, a fall may have been provoked by fatigue that may be a result of a late start or a biased evaluation of the route's length. The risk perception plays an important role, once it may be blurry due a focus on stratigrafy interpertration or reservoirs modelling.

Given this, it seems to have a need to develop different safety. In addition, when the geoscientist's work is in the field, in the outdoors, different risks arise in the outcrops, especially due the location of these: busy urban highways, rural highways, mountain trails, river crossing, crossing of cliffs, rock falling etc. There are risks that are common to the industry, such as falling from the same height, falling objects (in the case of outcrops, rock fragments) and falling in height, from small heights of the order of $2,00 \mathrm{~m}$ to great heights of the order of $30,00 \mathrm{~m}$. On the other hand, other risks arise, such as the attack of venomous animals, attack of wild animals of various sizes, thorn injuries, lesions by stinging plants and intense exposure to weather.

\section{Risks of Geology Field Activities: animals}

Since the first field works, even before the born of the modern geology, naturalists, philosophers, and enthusiasts of the natural sciences lived with the presence of various kinds of animals on the outdoors. Most of time, it was a peaceful and even symbiotic coexistence. However, in some cases accidents of various levels have occurred involving men and animals, from minor scratches, even fatalities. According with Gehrke et al (2010), accidents involving venomous animals in outdoors activities are still a serious problem in Brazil, both due to the number of reported cases, with an average of 5,000 spiders, and the severity presented, which can lead to death or sequelae capable of generating temporary disability. Other venomous animals, such as snakes, also have a high frequency of accidents on outdoors, not only in Brazil, but also in South Africa and Argentina, where geological field studies are performed. In Figure 1 shows a spider on the rocks of the Sigmóides outcrop of the Itajaí Valley Turbidite Field Course, in Santa Catarina State, Brazil.

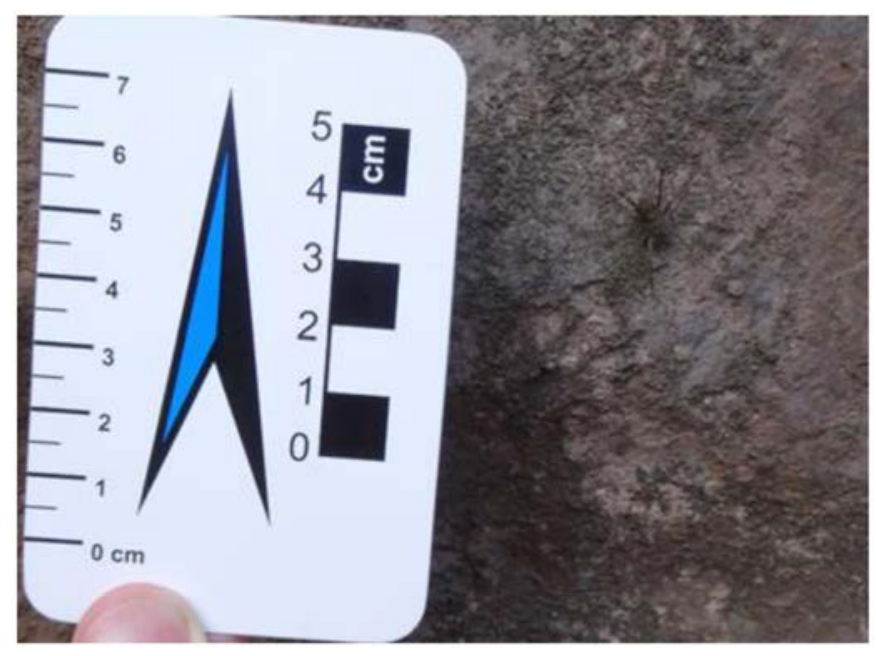

Figure 1-Spider on rocks of Sigmóides outcrop. 
It was not possible to determine which species of this spider, and whether it is venomous and endanger humans, as there were no biology professionals present at the time of this study. Even analyzing the photos by biology professionals, after the field studies were completed, it was not possible to clearly determine the species, but suspicions were raised that it is a species of the Ctenidae family, whose best-known member is the bananeira-spider, or family Pisauridae, which is a family of small, usually light, or gray-brown spiders that includes species known as garden-spider or nursery-spider. Although none of the biology professionals pointed out that the species found could be a brown spider, according to Gehrke et al (2010), the municipality of Ibirama, in the Itajaí Valley, is a place that has a large spider population genus Loxosceles. These animals are better known as brown-spider, for their characteristic coloration, but it is not the color their main property, but the potency of their venom.

\section{Risks of Geology Field Activities: electrical hazards}

The electrical hazards, in the outcrop environment, refers to two different risks scenarios: firstly, the natural electrical discharge, commonly known as lightning strikes, and secondly, electric shocks related to urban or rural power grid installations in outcrops. Since much of the fieldwork takes place in open, weather-prone locations, prior knowledge of the region in relation to lightning phenomena is required. Based on Biasi Gin, Pereira Filho, Beneti, \& Guedes (2012), Brazil is the country with the highest incidence of lightning in the world, with the Southeast and South Regions being the first and second largest, respectively. Once the geology field courses in Brazil occur mainly in these Regions, additional lightning safety requirements must be taken before and during field activities. Regarding electrical hazards arising from distribution grids, other safety measures should be taken, both in the outcrop and in their sight, as these are places where low and high voltage grids are commonly found. In the Figure 2 is an exemple of that, a pole of high voltage grid at Cedamavi outcrop sight of the High-Resolution Stratigraphy in Microbial Calcaries of Salta Province Field Course, in Salta, Argentina.

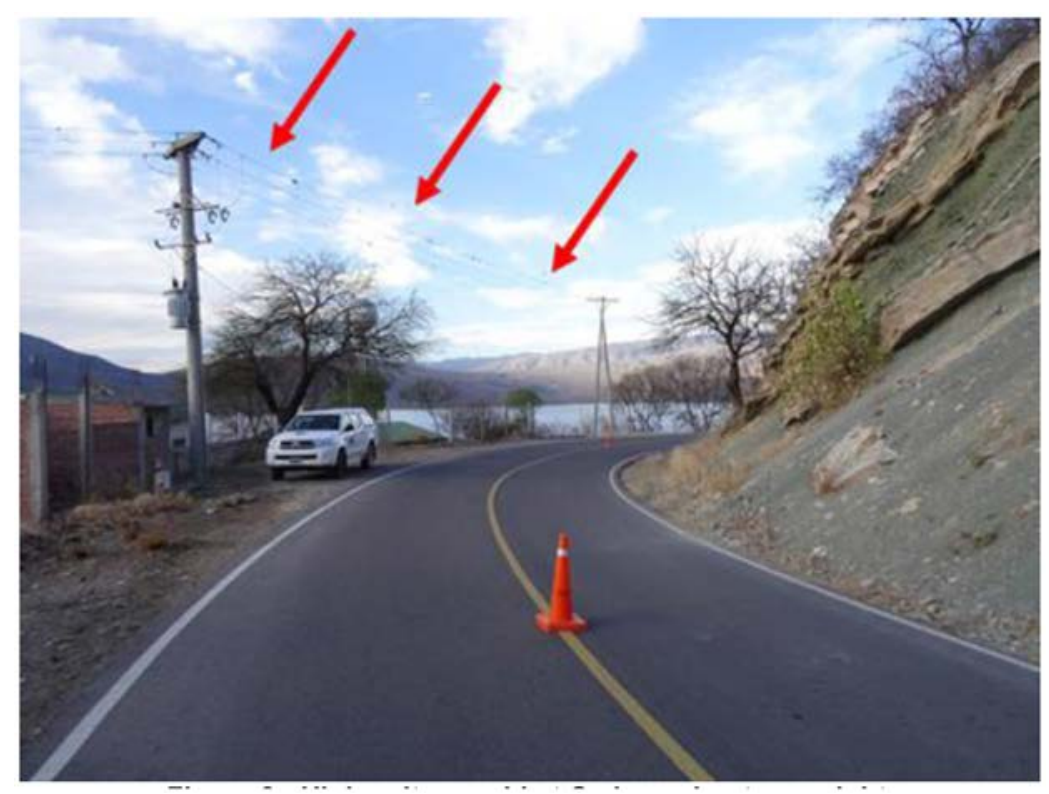

Figure 2-High voltage grid at Cedamavi outcrop sight.

\section{Risks of Geology Field Activities: roads and highways}

Almosf half of the outcrops of geology field courses are located on highways, roads and dirt roads, which add a severe risk to field activities: vehicles. These vehicles are a dynamic, semi-predictable element that stores a great deal of energy at high speeds, enhancing damage and injury on impact. An important fact to note in this context is that the opening of mountains and landscapes for the passage of highways and 
roads sometimes exposes excellent outcrops for study, which were hidden by their own structure, soil or vegetation. In this way, a human action, besides altering the geography of the region, reveals a side of geography hitherto hidden, which is now part of the field studies of geoscientists.

In this new scenario of study, driving speed is the main factor leading to highway accidents, on the highway itself or on its shoulders. When a vehicle makes a turn, a high speed will result in an excessively large lateral force, so the vehicle will drive to the shoulder, where the geocientists are performing their studies (Cheng, Cheng, Zhang, \& Sun, 2019). In this sense, reduce the vehicles speed is a crucial protective measure to promote safety. Thereby, it is necessary take measures to show drivers clearly and pointedly that are people working in the shoulders, forcing them to reduce their speeds. In the Figure 3 , it is possible to verify the signaling cones, signaling dummy and reflective vests as safety measures for field activities in the highway shouders of the Seabra outcrop, in the High-Resolution Stratigraphy of Chapada da Diamantina Field Course, in Bahia State, Brazil.

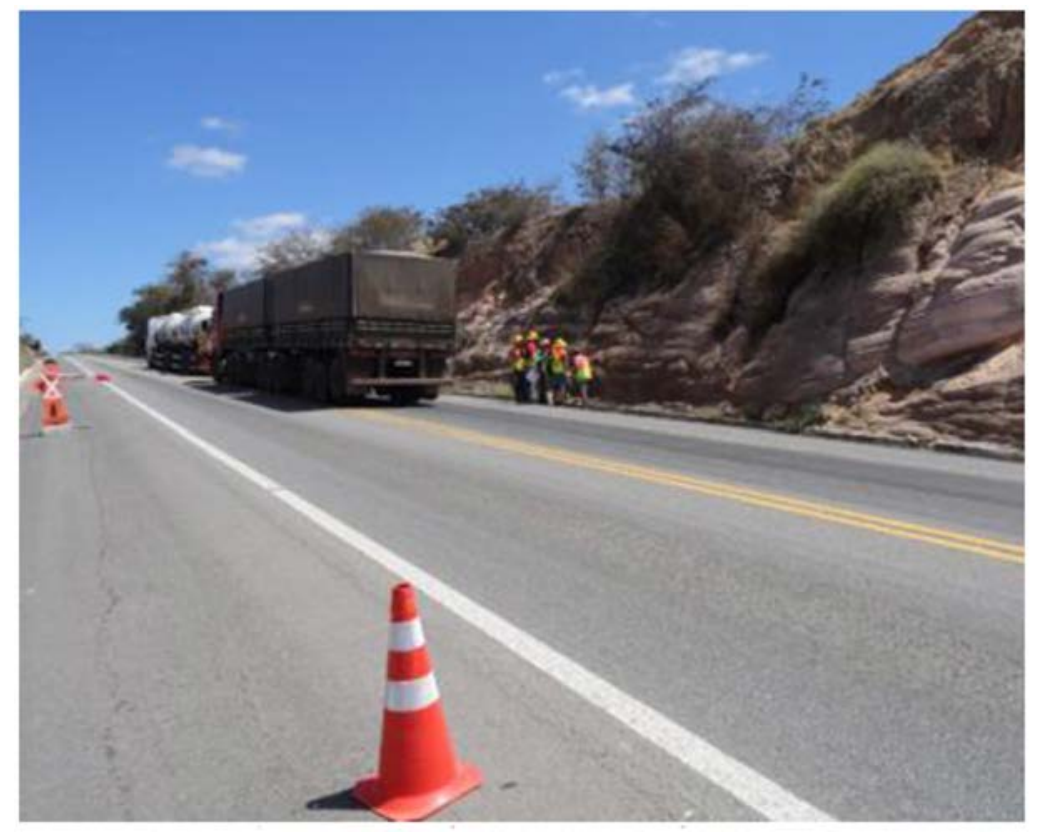

Figure 3-Highway safety measures in Seabra outcrop.

\section{Risks of Geology Field Activities: falls}

From the simplest to the most complex work activities, falling is one of the most present risks. Falling presupposes a loss of balance, but it is not limited to it alone. Briefly, from a labor point of view, the fall can be divided into three ways: 1) fall from one's height, 2) fall from heights, 3) fall of objects in the workers. Analysing the causes of why workers got injured in their workplace, fall appears as one of main reasons. Even when workers are using personal safety equipment, falls can cause injuries, because that equipment reduces the consequences of an injury, but do not prevent a fall. Workplace injuries by falls are all too common at construction sites, where typical injuries include falling from scaffolding, getting hit on the head, and slipping (Dekker, 2019).

In the field activities of geoscientists, it is also possible to see that the fall is present in these three distinct ways, as well as industrial areas. In this sense, there is some similarity and protective equipment, especially individual ones, can also be a safety solution for field studies in outcrops. And indeed, as can be seen in Figure 4, geoscientists, in order to protect themselves from falling from their own height, are wearing yellow hardhats to protect from injuries, especially head concussion. These concussions can happen due to loss of balance in the rock fragments that are in the soil, as can be seen in the Ponta do Pai Vitório outcrop, in the Structural Geology of Cabo Frio High Field Course, in Cabo Frio and Búzios, Rio de Janeiro. 


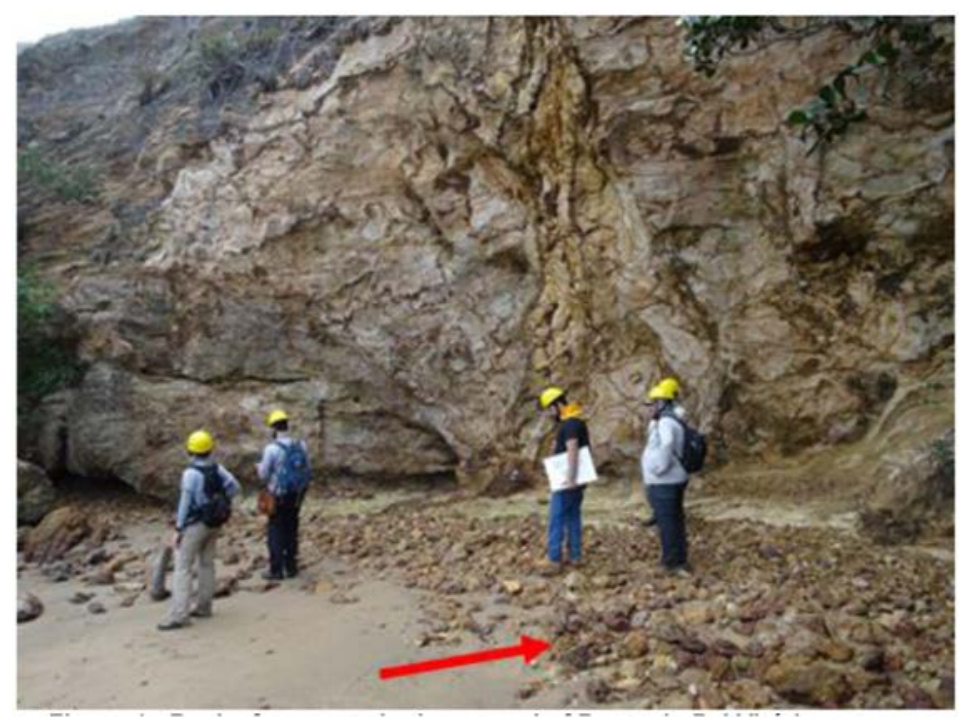

Figure 4-Rocks fragments in the ground of Ponta do Pai Vitório outcrop.

Another scenario of fall, very common in outcrops, is the fall form heights, once several outcrops are located in high landscapes, far from urban areas, and with very little human alteration, but may present, depending on the region, great weathering in the rocks, leaving them brittle, which increases the likelihood of falls. In the outcrops comprised by this study, in Brazil, Argentina and South Africa, a great variety of landscapes and heights were observed, starting from just 1,00m in loose blocks in Salta Province, Argentina, to heights of more than 40,00m in the Karoo Basin, in South Africa. In Figure 5, it is possible to see, at Kannalkop outcrop, in the Karoo Basin, the great height between the outcrop study level and the base of the mountain. A fall from this height without adequate protections would be fatal. In addition to the risk of falling, in this region of Africa, the presence of snakes - notably Cape Cobra - and baboons is very common, which greatly increases the risk of injury and even fatalities. This outcrop is part of the studies of Deepwater Reservoir Architecture and Heterogeneities - Karoo Basin Field Course, in South Africa.

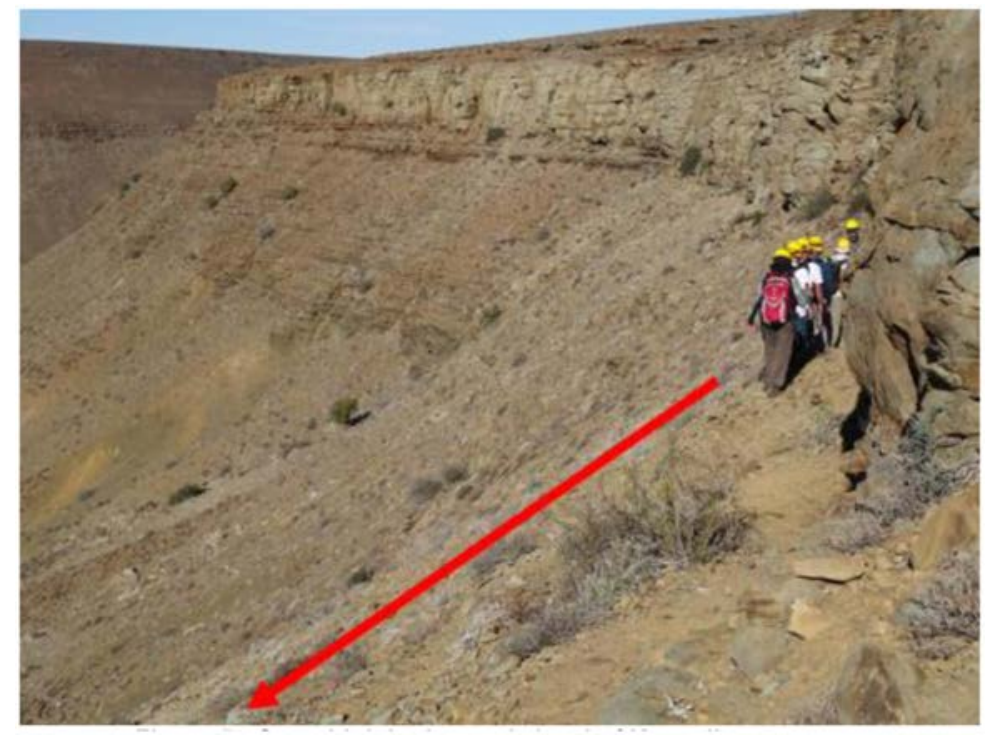

Figure 5-Great high in the study level of Kannalkop outcrop.

The last scenario considered is the fall of objects in the workers, which in this study relays on fall of rock fragments in the goecientists. It is important to note, however, that depending on the size of 
the rock fragment, personal protective equipment, notably the hardhat, does not provide the necessary protection, requiring another barrier, which is the safe positioning. Despite being an effective barrier, the safe positioning is not a technological barrier, but a behavioral one, which will depend on subjective control elements, such as risk perception and the company's organizational culture. The organizational culture is also the safety culture of a company, once its is the interaction of individual and coletive risk perceptions, attitudes, competencies and patterns that determine the coletive commitment to promote safety in all activities (França, Hollnagel, dos Santos, \& Haddad, 2019).

In addition, although it seems unlikely, there is also the possibility of falling objects other than rock fragments, such as bottles, metal parts, branches and parts of the power grid distribution. This is because many of the outcrops are located on the roadside where these objects may fall or be thrown from vehicles, or in urban areas where there are constructions. In the Figure 6 is possible to see a sequence of rocks falling, from the top of the outcrop, to the ground. Note that in the middle, there is a huge rock fragment, showing signs of breakdown of the outcrop, indicating a possible fall. This scenario is present in the Puente Picún Leufú outcrop, in Neuquén Province, Argentina, where is placed the Stratigraphy, Sedimentology and Depositional Geometries - Neuquén Field Course.

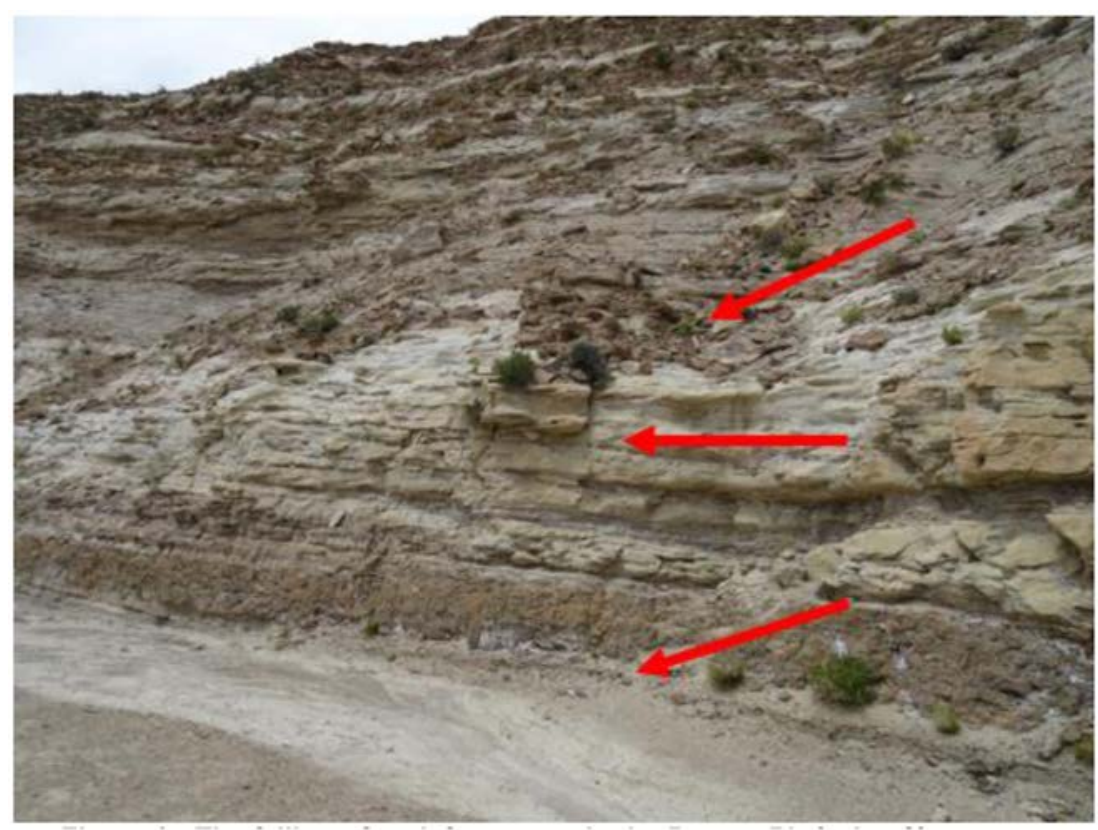

Figure 6-The falling of rock fragments in the Puente Picún Leufú outcrop.

\section{Risks of Geology Field Activities: weather conditions}

Although working in the outdoors, like outcrops, may offer upsides, it is not all sunshine and blue skies. According with NIOSH (The National Institute for Occupational Safety and Health), outdoor workers are exposed to many types of hazards that depend on their type of work, geographic region, season, and duration of time they are outside. Employers should train outdoor workers about their workplace hazards, including hazard identification and recommendations for preventing and controlling their exposures. Moreover, as far as geoscientists' fieldwork is concerned, weather conditions are a crucial factor for study activities. Snow, heavy rain, storms, intense wind and sun are the most unfavorable weather conditions for field studies, potentially causing injuries and even fatalities. The cold and heat associated with these unfavorable conditions are the elements directly linked to heat stroke, hypothermia, skin lesions, headaches, unconsciousness and breakdowns.

In the Figure 7 it is possible to see the intense sun in the Paardefontein outcrop, in the Karoo Basin, South Africa. Note that all geocientists are wearing dark glasses, hats and protective clothes due the intense sun. 


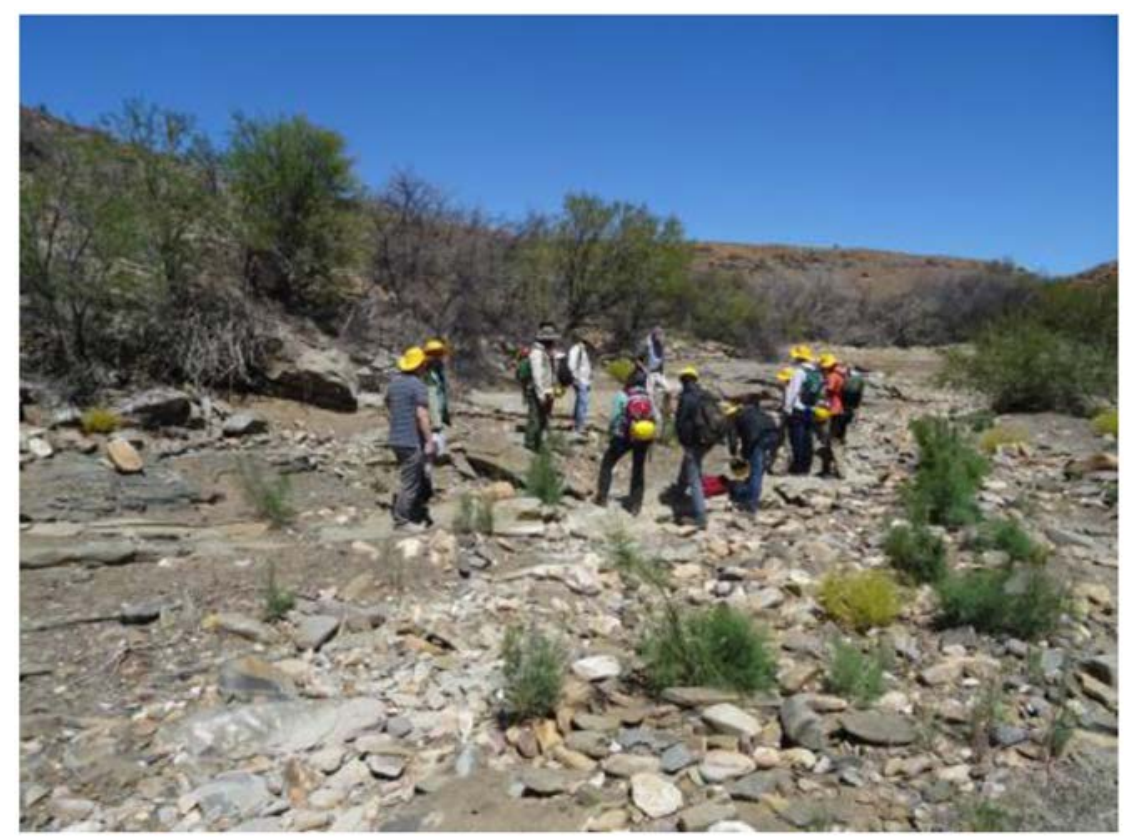

Figure 7-Intense sun in Paardefontein outcrop.

In turn, illustrating another situation of weather conditions in the field, Figure 8, shows that geocientists are wearing plastic ponchos to have protection from a light rain in the Placa Hotel outcrop, in the HighResolution Stratigraphy of Chapada da Diamantina Field Course. Note that the last in the line has an umbrella in his hand, something also useful in situation like that. However, as reported by OSHA (2016), rain is a risk that can potentially escalate to a thunderstorm, especially in tropic regions such as Northeastern Brazil. Thus, risk perception and situational awareness are key elements in worker protection, even with light rain, because lightning strikes can occur without warning.

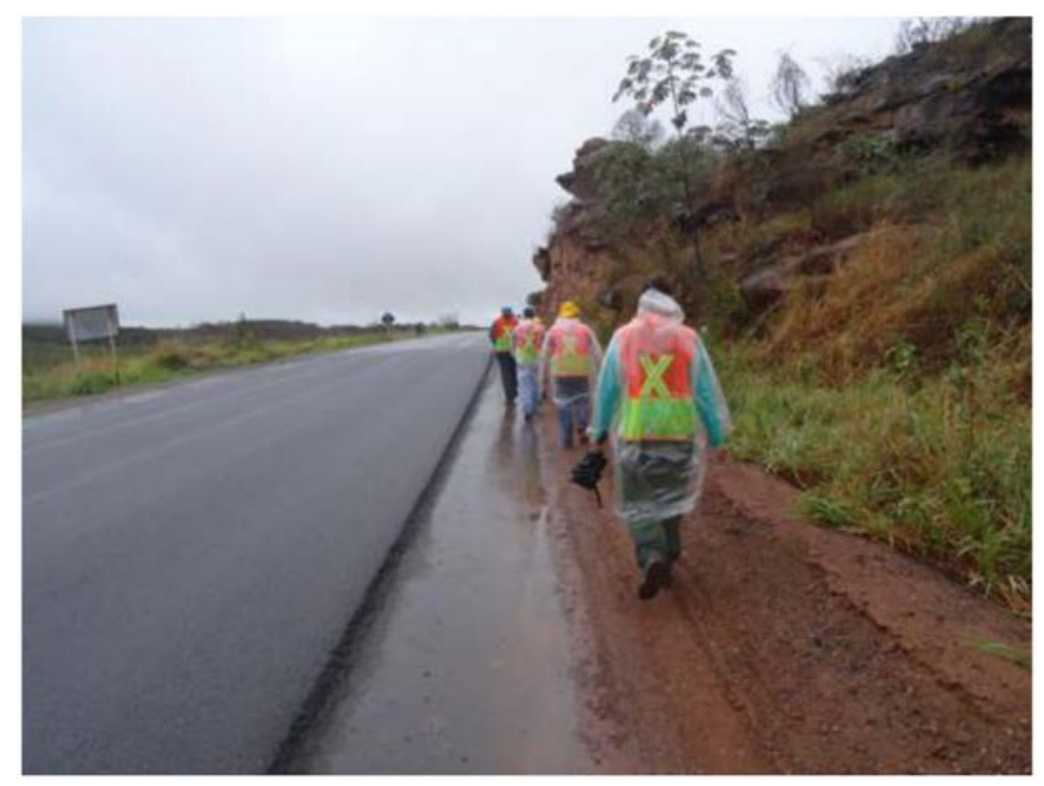

Figure 8-Light rain in Placa Hotel outcrop.

\section{Creating a safety culture in the field}

Safety is a collective construction of all workers and the company. In the outcrops of geological field studies, could not be otherwise. Whether in Brazil, Argentina or South Africa, the joint work of geologists and 
safety engineers has been the driving force behind building a safety culture in geological field activities. Sometimes the geologist focuses his senses and understanding on outcrop studies, clouding additional risks that may be present. On the other hand, the safety engineer does not understand the distinct nature and interaction of geologists with outcrops, having a shortsighted view that the same safety rules as an industrial plant apply to outcrops. None of this has occurred in this study because the integrated, concerted and harmonious action between geologists and safety engineers has promoted something distinct and unique: a deeper understanding of all the risks of field activities as well as an understanding of the importance and nature of the work of geoscientists in the field.

Despite all the developments observed here, this joint work is still ongoing, and the process of continually improving a new understanding and perception of risk can and should be developed in all activities and regions where field activities exist, promoting a genuine culture from geological studies of outcrops to the wellhead of an offshore oil rig. The interaction, exchange of knowledge and competences in these works was so fruitfull and effective that sometimes was impossible to distinguish between safety engineers and geologists, because they were working so closely that both were doing the same actions. As can be seen in Figure 9, the safety engineer is not only wearing the geologists gear, but also interacting with the outcrop just like geocientist, at Loskop outcrop, in the Karoo Basin. Note that the safety notes are being made in the geology field booklet, gathering geology and safety information here, building a new field culture where safety is natural in all activities, adding value to the already recognized and distinguished work of geoscientists. For Hollnagel (2014), the variabilities of human performance in their work is exactly what have the work done safely and, when understood and congregated with others variability, can build strong and lasting safety culture

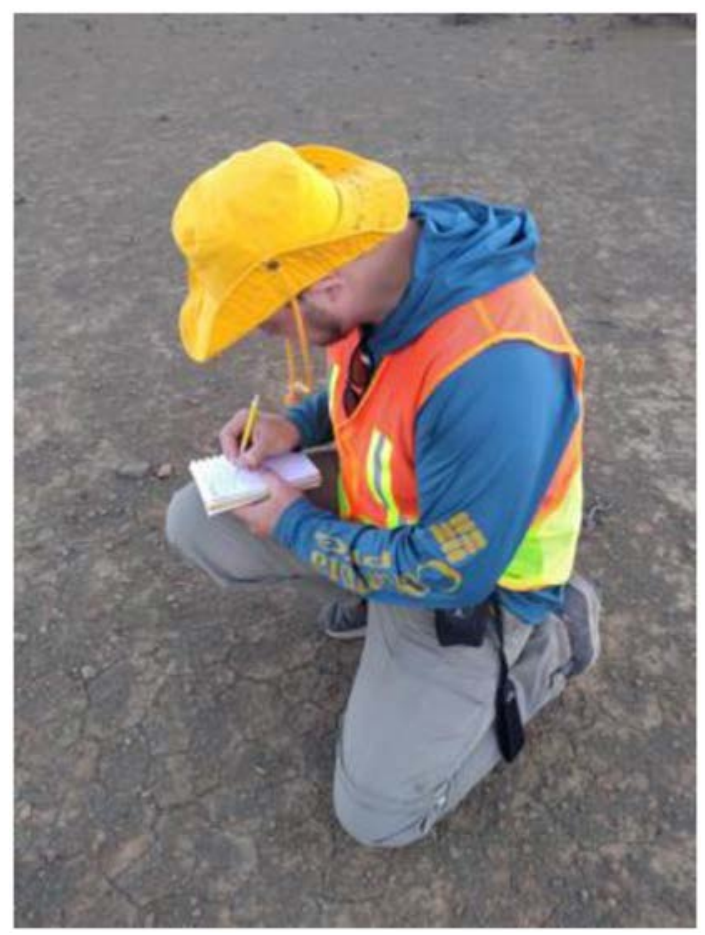

Figure 9-Safety engineer making safety notes in Loskop outcrop.

\section{Conclusions}

In all upstream activities, is important to balance risks and opportunities, and in the outcrops filed studies would be not different. One of the most important steps in minimizing risk by understanding where and how the work is performed, and in this sense, the combined work in the field of geocientists and safety 
engineers promote a wider perspective of risk, starting by a deep understanding of the activities, lead by the geocientists. In this study, since the first field course, there was not work division, such as the risk assessments done only by safety engineers and outcrop interpretation and studies done only by geocientist. Frequently, the safety engineers asked the geocientints like "how can I do this", "how you perform this", "how can we do differently", "can you teach me how to do that" and "can you help me to understand that". They haven't imposed any safety rules or procedures just for his competence in the matter. They first understood how the work is done by asking and experiencing the routine of geoscientists in the field. This was somewhat different because it allowed safety engineers to realize that field geology work cannot be simply compared to any regular work in an upstream facility; it is much more than that, although some risks are present in both. In another hand, the geocientists often asked the safety engineers like "how can I do it safer", "do you think it is safe", "how can we do this without risks", "let's do it together" and "can you help me to understand that". In fact, "let's do it together" can be the prhase that summarizes this study, once it was exactly what happened: a work together, where safety engineers gave up their paradigms, rules and procedures to understand and experience the differentiated work of geoscientists. In turn, geoscientists have also allowed themselves to break paradigms and have accepted a new, safer way to do something they have been doing for decades. Respect, exchange and knowledge were the key elements that defined this work, and buildind a new culture in field geology activities, a new four-handed safety culture, with safety engineers and geoscientist working in cooperation.

\section{References}

Cheng, G., Cheng, R., Zhang, S., \& Sun, X. (2019). Risk evaluation method for highway roadside accidents. Advances in Mechanical Engineering, 11(1), 1-12. https://doi.org/10.1177/1687814018821743

Cross, T. A. (1997). Amanz Gressly 's role in founding modern stratigraphy, 7606 (December 1997). https:// doi.org/10.1130/0016-7606(1997) $109<1617$

Dekker, S. (2019). Foundations of Safety Science - A Century of Understanding Accidents and Disasters. (Taylor \& Francis Group, Ed.) (1st Ed.). Boca Raton FL: CRC Press.

Du Toit, A. L. (1952). Comparação geológica entre a América do Sul e a Africa do Sul (Du Toit, A). Rio de Janeiro: SERGRAF do IBGE.

Forrester, J. D., Tran, K., Tennakoon, L., \& Staudenmayer, K. (2018). Climbing-Related Injury Among Adults in the United States: 5-Year Analysis of the National Emergency Department Sample. Wilderness and Environmental Medicine, 29(4), 425-430. https://doi.org/10.1016/j.wem.2018.05.006

França, J. E. M., Hollnagel, E., dos Santos, I. J. A. L., \& Haddad, A. N. (2019). FRAM AHP approach to analyse offshore oil well drilling and construction focused on human factors. Cognition, Technology \& Work. https://doi.org/10.1007/ s10111-019-00594-Z

Gehrke, R. S., Souza, Á. H., Gonino, G. M. R., Oliveira, I. M. de, Caxueira, M. R., \& Hennig, E. L. (2010). Levantamento de Espécies de Aranhas do Gênero Loxosceles Heinecken e Lowe, 1832 no Município de Ibirama, Santa Catarina.

Gin, R. B. B., Pereira Filho, A. J., Beneti, C. A., \& Guedes, R. L. (2012). Estudo de descargas elétricas atmosféricas no Sul e Sudeste do Brasil, (1226), 1-9.

Klemm, D. D., \& Klemm, R. (2001). The building stones of ancient Egypt - A gift of its geology. Journal of African Earth Sciences, 33(3-4), 631-642. https://doi.org/10.1016/s0899-5362(01)00085-9

Schwab, M., Hauschke, N., \& Hellmund, M. (2012). Johannes Walther (1860-1937), dem Begründer der Faziesregel und Ordinarius der Martin-Luther-Universität Halle-Wittenberg zum 150. Geburtstag. Hallesches Jahrbuch Für Geowissenschaften, 32(September), 1-18. Retrieved from http://public.bibliothek.uni-halle.de/index.php/hjg/article/ view/11

Vanpoulle, M., Vignac, E., \& Soulé, B. (2017). Accidentology of mountain sports: An insight provided by the systemic modelling of accident and near-miss sequences. Safety Science, 99(November 2013), 36-44. https://doi.org/10.1016/ j.ssci.2016.11.020

Winchester, S. (2004). O Mapa que mudou o Mundo: William Smith e o nascimento da Geologia moderna (1 Edição). São Paulo: Record.

OSHA - DTSEM FS-3863 (2016). Lightning Safety When Working Outdoors. Fact-Sheet Lightning Safety. Occupational Safety and Health Administration (OSHA) and the National Oceanic and Atmospheric Administration (NOAA).

Hollnagel, E. (2014) Safety-I and Safety-II - The Past and Future of Safety Management. 1 st. Surrey: Routledge. 